Arquitectura e Ingeniería en Iberoamérica: hombre, naturaleza y ciudad

\title{
tercer premio
}

\section{VIVIENDA: "SOPORTE MODULAR Y PARTICIPACIÓN"}




\author{
"VIVIENDA: SOPORTE MODULAR Y PARTICIFACION" \\ Jaine Mogollón Sebá, Arquitecto \\ P.As Universidad Naciona] de Colonbia - Manizales
}

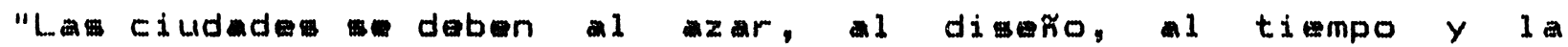
memoria en otras palabras, son obra de 1 a gente, regulada por el gobierno, modificada por el tiempo y preservada por la memoria"

Teodoro Gonzalez de Leon
\end{abstract}

RIESIMEN:

Ante 1 as corracteristicas que reviste el problema habitacional colombiano y la imposibilidad del Estado y la comunidad para resolverlo, en 1 as condiciones economicas, : cuenta tambien 1 as posibilidades que brindan 1 as reformas

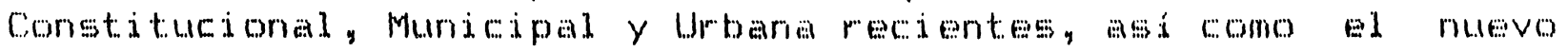
rumbo que seguramente tomaran la industria productora de materiales y 1 as entidades publicas y privadas dedicadas a 1 a solucion del deficit y de 1 a Ealidad de la vivienda de interso sor. y construir viviendas que favorecezcian economicamente al usuario y 1 e permitan participar en la identificarión de sus necesdades y dar respuestas espaciales acordes a sus gustos y posibilidaces. Garantiza seguridad al situarse 1 as viviendas sobre una estructura de soporte ambientalmente sana y constructivamente

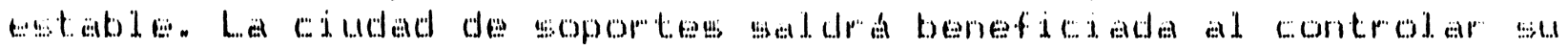
densidac y 1 a extension de servicios, vías y transportas. 


\section{EL. FROELLMA ES DE CANTIDAD Y DE CALIDAD:}

La 1 iteratura colombiana sobre el protilema de 1 a vivienda se dedica, generalmente, a mostrar estadisticas y a señalar 1 a magnitud del deficit habitacional en forma de diagnosticos mecónicos encaminados a mostrar la impotencia del Estado para resolverlo. Nurice se plantean soluciones realizables porque nos mantenemos entre dos ideas irreconciliables: la de $10 s$ enemigos del. Eistema que como unica salida encuentran la transformacion total de los mecanismos del Estado para iniciar las soluciones sociales $y$, por otro 1 ado, 1 a de $10 s$ especuladores inmotili arios que solo persiguen el beneficio particular torpedeando cual quier i dea reformist.a.

Colombia, al i gual que otros paises tercemundistes, mantiene un aceler ado proceso de urbanizacion que se ha visto reflejedo Especialmente en 1 a subnormalidad urbana y el. mayúculo deficit habitacional. Colombia es un pais de regiones y ciudades, en esto se diferencia de otros paises latimoamericanos donde generalmente se ha concentrado 1 a pobleción en sus ciudades capitales.

Existen regiones muy marcadas economica y culturalmente: la region atlántica, la pacifica, 1 a andina, 1 a orinoguia y $1 a$ amazonia $y$ en ellas 1 as comunidades han desarrol ado, de acuerdo a sus posibilidades gustos y recursos, diferentes organizaciones

espaciales y han construido sus casas con diferentes tecrologias constructivas, razones que invalidan cualquier solucion de corte

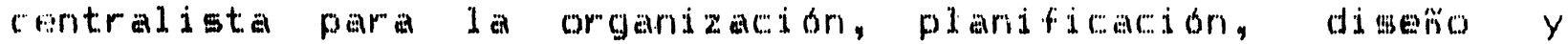
produceión de viviendas.

Dentro de 1 a REGION ANDINA se Encuentra la zona conocida como "EJE CAFETEFO" que comprende los Departamentos de caldas, Fisaralda y Quindio, y parcialmente los de Antioquia y Valle del cauca. Su altitud esta comprendida entre 1.000 y 2.000 mts. $50 b r e$ el nivel del mar y temperaturas entre 13 y 24 grados centigrados. Su economia esta basada en el cafe, habiendo tambien cultivos de frutas y ganader ía.

Sus bosques estan poblados principalmente de Arboloco, Nogal y Gambusas Guadua.

\section{1 LA CANTIDAD:}

Se dice que aproximadamente el $30 \%$ de 105 colombianos vivimos en zonas de riesgo natural, correspondiente a 1 a cadena volcánica (zona andina) $y$ a 105 Valles y 11 anos innundables.

En el sector rural, donde viven 8.8 millones de habitantes, la tercera parte de ellos viven en la pobreza absoluta y el $50 \%$ de 105 hogares tienen insatisfechas sus necesidades basicas, o sea aproximadamente 850.000 hogares.

En el sector urbano, de 4.2 millones de viviendas, el $40 \%$ se consideran no apropiadas esto equivale a 1.6 millones, para un total de 2.450 .000 casas que habria que mejorar o remplazar.

Cualquiera que sea la cifra del deficit, 10 cierto es que mas dramatico que el es 1 a imposibilidad de las gentes para adquirir 1 as casas que se construyen. Un estudio de 1 a demanda efectiva de 
vivienda elaborado por CAMACOL (Camara colombiana de 1 a construccion) - ver "La reforma urbana, el Upac y la vivienda social", de Fabio Giraldo Isaza, en Fevista Economía colombiana, Marzo-faril de 1989 - en las 10.ciludades más grarides del pais rios muestra que solo existe demanda potencial para 270.000 viviendas, de 1 as cuales el $69 \%$ se requieren con prerio menor a 2.000 upacs (t) 8.500 .000 .1 upac = 159 a a 1 a fecha) que equivaldria a 10 definido como vivienda de interes social según la fieforma umbana. sin embargo, estas viviendas solo pueden ser adquiridas por familias con ingreso minimo de 5.5 salarios minimos $\left(4 S_{\text {t }}\right.$ $497.15)$, o sea por el $30 \%$ de 1 a población con mayores ingresos. Existe entonces un desfase entre el deficit y 1 a demanda, razon que 11 evó al actual gobierno a crear el Subsidio Familiar de Vivienda para 1 as que tengan un valor inferior a 135 salarios minimos (US : 12.000 ).

Las entidades y organizaciones no han sido capaces de construir 1 as viviendas necesarias, ni existe una demanda efectiva para el1 as por falta de capacidad economica de pago. A lo anterior se agregan los altos precios de la vivienda, determinados por el alto precio de la tierra, que en la vivienda popular equivale al $30 \%$ del valor de la casa, y por los altos costos de obras de urbanización y de construcción, calsados por el uso de metodos constructivos artesanales, monopolio en 1 a produccion de 105 principales materiales utilizados, discontinuidad en 1 a investigacion y desarrollo de tecnologias, sistemas arcaicos de contratación, elevados gastos financieros, altas utilidades de 10 constructores y demorados tramites burocraticos.

Ante esta situacion las salidas experimentadas con 1 a disminucion del tamaño de los lotes y 1 a paradogica expansion urbana por 1 as soluci ones unifamiliares, 1 a reduceion de vias, el desarmollo progresivo de 1 a infraestructura de servicios, 1 a reduceion de áreas en la vivjenda, la disminucion de las especificaciones constructivas, la uniformidad, 1 a autoconstruccion,etc. no han terido exito hasta el momento y justifican una nueva propuesta.

\subsection{LA CALIDAD:}

El aspecto cualitativo es tan importarite como el del deficit. Definimos vivienda como el lugar de mayor significación humana por la intensiad con que ge dan en ella 1 as pelatoiones afectivas y donde el hombre toma el descanso fisico y sicologico para poder desarpol 1 ar sus actividades cotidianas. Trabajamos 1 a casa con la idea de lugar, no como un espacio definido cual quiera, sino como un especio para la existencia a espacio existencial que recesariamente conlleva 1 a idea de posesion y pertenencia.

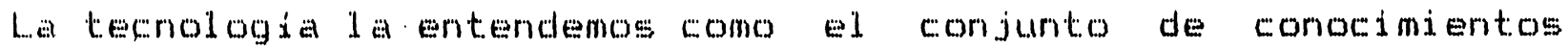
tecricos que posee la sociedad o un grupo social determinado y gue le permite, en un momento dado, resolver los problemas que le plantea su camino al desarpollo. recrologia vista como 105 procedi mientos necesarios para una eficiente materializacion del entorno $y$ que se adecha a los requerimientos economicos, ambientales y cul turales de cada regió, siempre con la meta de su desarrollo e industrialización. 
Los pobres de Col ombia viven:

En "casas" construidas por ellos mismos en lotes invadidos.

En viviendas, autoconstruidas a no, en lotes de urbanizaciones "pir"atis".

En inquilinatos.

$\gamma$ en los alojamientos de masas. (Vivienda masiva seriada)

Ninguna de estas "soluciones", en su inicio, puede considerarse vivienda, pues 5 dlo con el esfuerzo y dedicación de sus usuarios alguras de $e 11$ as 10 corisiguen con el tiempo.

\section{1. $\because$ LA VIVIENDA SUENOFMAL:}

Las casas en lotes invadidos, las construidas en barrios "piratas" y 10 snquiliratos, son 1 as lutilizadas por las familias má potores. Según el CENAC de todas las casas que se construyen en el pais, 1 as subnormales representan el 40\% a nivel urbano. Estas viviendas se caracterizan por su deficiente calidad pues en Ellas no se 11 enan 105 minimos requisitos de habitabilidad, como son:

-... Adecuada superficie util

- Estabilidad

- Seguridad

Frotección contra agentes externos

A...- Aisimi anto

- Confort

-..- Privacidad

- Uso adecliado del espacio

- Il luminación y ventil ación natural

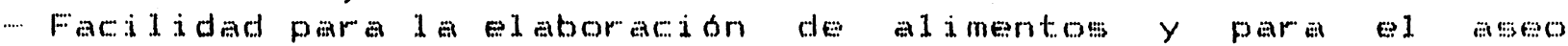
personal

- Jnfraestructura de servicios (alcantarillado, acueducto, energia, telefono)

.... Sin mencionar 10 equipamientos comunitarios, 1 a salubridad y estetica ambiental, el descanso y 1 a recreación.

\subsection{LA VIVIENDA AUTOCONSTRUIDA INSTITUCIONAL:}

La autoconstrucción que alientan las entidades oficiales, se motiva en terminos económicos por la incapacidad demostrada para resolver el problema de 1 a vivienda, mas que como 1 a idea de una perticipacion efectiva de 1 a comunidad en 1 a toma de decisiones y en la creación de su habitat. Ya vimos atrás como el mayor deficit qolpea a 1 as clases mas pobres y que estas no tienen capacidad de pago. En los programas regulares institucionales mukas familias para lograr la adjudicacion de lona casa tienen que inflar sus ingresos para mas terde no poder pagar sus cuotas $y$ ser desalojados.

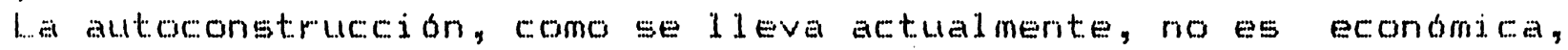
pues como los usuarios no saben construir tienen que subcontratar con aloaniles expertos, y si ellos construyen directimente se desperdician $10 \mathrm{~s}$ materiales, se aumenta el tiempo de

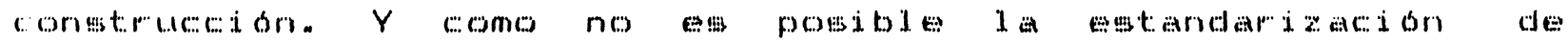
elementos constructivos y su compra masiva, 105 precios suben. Los djeEños de Estos programas generalmente obedecen a patrones y es guemas obsoletos en los que no ha tenido ningura ingerencia el

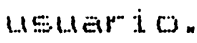




\subsection{EL ALOJAMIENTO DE MASAS:}

Fracticamente todas 1 as experiencias colombianas en materia de vivienda han sido orientadas a resolver el binomio costo-tiempo, y dentro de esta 1 inea la respuesta ha sido la repeticion o agrupaciones con interminables e impersonales filas de casas o edificios identicos, que 1 as comunidades rechazan inmediatamente porque consideran que asaltan su personalidad y su libertad.

El alojamiento de masas (AM) es aceptable solamente como emergencia pero no puede ser planteado como un fin porque un alojamiento verdadero debe ser un acto civilizatorio y civilizacion es 1 a interaccion de los hombres, sus actividades y su medio ambiente por 10 que a cada parte del medio fisico le corresponde una arquitectura diferente.

La sola participacion del usuario en la construcción como en El caso de los programas de autoconstrucción no es suficiente: es recesario que 105 usuarios hagan contacto con 105 tecricos para decidir la configuracion inicial de 1 a casa y 1 as posibilidades de transformación posterior, puesto que habitar, como nos 10 enseña Martin Heidegger" (1951), "significa, estar contento, ser 11 evado a 1 a paz, quedar en paz. La palabra paz Eignifica lo 1. ibre..". Para habitar se debe dar la posesion y "algo 11 ega a nuestra posesion cuando le imprimimos nuestro signo, cuando le damos nuestro nombre, cuando 10 profanamos, cuando muestra muel1 as de nuestra propia existencia" (Habrat:en 1.975). Vivi enda, en este orden de ideas, es un proceso que existe antes, en $y$ despues de 1 a construcción pensar en 1 a construcion como una 501 cuion es un concepto funcionalista de naturaleza tecnica que Exiluye al usuario y convierte a la casa en cosa o sea, en un hectio impersonal.

Uha vivienda debe permitimos realizar actos por nosotros mismos,

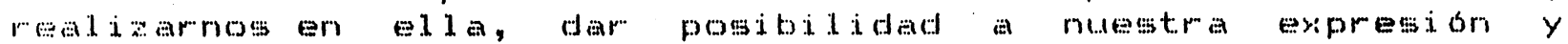
adquirir con el tiempo un toque de muestra personalidad.

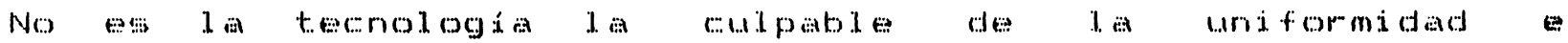
jomersonalidad del alojamiento de maseas. La normalizacion, prefabricacion 0 industrializacion de partes puede permitir

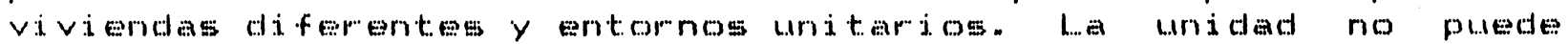
confundirse con uniformidad; unidad es una expresion o convenio cultural al que un grupo social ha 11 egado, pero como individuo el hombre es unico. El AM se encuentra con luna contradicción: necesita satisfacer 10 e regluerimientos de la gente, pero utiliza la uniformidad que la gente no tiene.

E1 AM plede harer clasificaciones por edades, oficios, sexos,

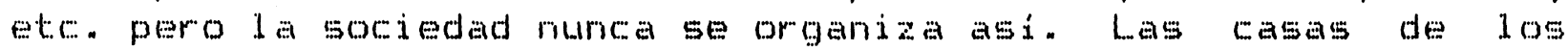
jovenes, las cases de 105 ancianos, 1 as casas de 10 ceapinteros, 1 as casas de 105 poetas, todas 1 as cas No existe un modelo.

El hectio que hemos comprobado, haciendo investigacion de campo, con los alumos del Seminario de Vivienda de interes social en 1 a universidad, en 105 Earmios Malhabar y Aranjuez de 1 a ciudad de Manizales, es que las casas del AM son rechazadas por sus welarios, quienes las transforman hasta 1 ograr 10 que ellos entienden como vivienda. 
LA GENTE CAMEIA LAS CASAS EN SERIE

Fesultados de 1 a encuesta. Harrio Malhabar (Mamposteria)

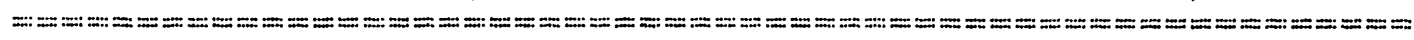
Han modificado sus viviendas. . . . . . . . . . . . .89.8\% Han cambiado 1 a distribucion de 10 espacios.....68.5\% Han adicionado construccion...................74.0\%

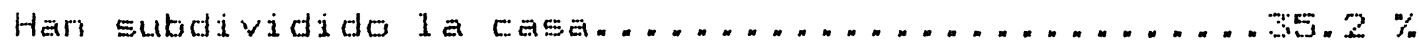
Han subdividido y ampliado la casa....................$\%$

Los materiales predominantes en la construccion de las casas, no modificaron la situación anterior, en sector del mismo Barrio Malhabar construido en guadua $10 s$ resultados fueron similares.

\section{LA GENTE CAMBIA L...SS CASAS EN SEFIE}

Resultados de la encuesta. Harrio Mal habar (Guadua)

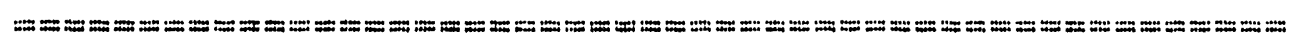

Han modificado sus viviendas. . . . ................ . . . . $3 \%$

Han cambiado la distribución de los espacios.....66.7\%

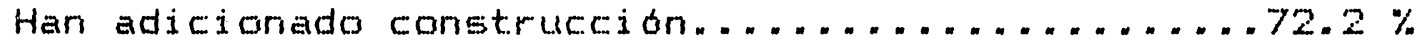

Han subdividido 1 a casa.................................

Han subdividido y ampliado 1 a casa...................

\section{LA GENTE CAMEIA LAS CASAS EN SERIE}

Fesultados de 1 a encuesta. Garrio faranjuez (Mamposteria)

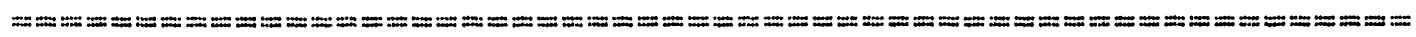

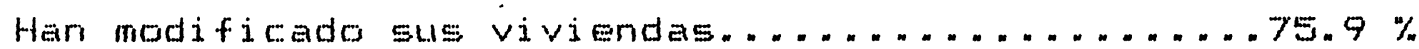
Han cambiado 1 a distribucion de 105 espacios.....57.4\% Han adicionado construction. . . . . . . . . . . . . . . . . . . . . . Han subdividido 1 a casa................................ Han subdividido y ampliado 1 a casa.............5. . . $\%$

Las causas principales de 1 as modificaciones fueron: EAFRIO MALHAEAF

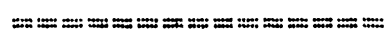

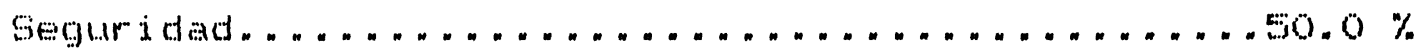

Ampliar los espacios................................

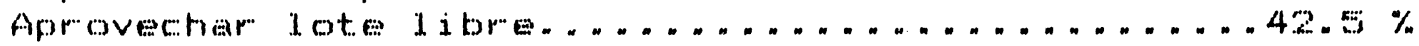

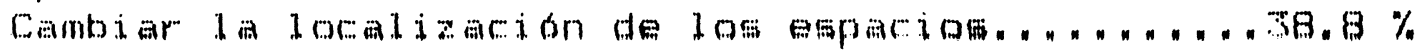

Cambio en 1 a composición famili ar"................5. . . . . .

\section{BAFRIO ARANJUEZ}

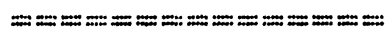

Aprovechar lote 1 ibre........................... $\%$ Necesidad de rentar una parte de la casa. . . . . . . 42.6\% Ampli ar 10 espacios.......................... $0 \%$ Mejor ar iluminaci on y/o ventilación...............5. $2 \%$ Cambio de uso de 105 espacios.........................

Ademis se pueden encumer ar calisas como: Necesidad de ideritificación

Cambios en 1 as condiciomes económicas

Frivacidad

Aparjcion de nuevos materiales

Cambios en el entorno inmediato, etc. 
Informes de la Construcción, Vol. 44 n. 424 , marzo/abril, 1993

No cabe, entonces, 1 a culpabilidad que se atribuye al arquitecto en la casa individual, de no saber interpretar las necesidades y gustos del ciliente. El protiema es diferente, se trata de la imposibilidad por parte de los arquitectos de resolver con una respuesta arquitectónica problemas y programas diferentes.

\section{SOPORTES - UNA SOLUCION ALTERNATIVA}

Muestra proplesta para el desarrollo de planes de vivienda de interes social, ante el frecaso y la impopularidad de los planes masivos de unidades unjfamiliares seriadas, está basada en el metodo de "Viviendas Adaptables" que presentó el SAF lStichting Architecten Fesear(ch), 1 ider ado por el Arquitecto N.J Habraken, en la Convención de invierno de la Asociación de Arquitectos Holandeses (1965), actaptada a nuestra realidad economica y tecrologica $\check{y}$ posibilitada por las reformas constitucional, municipal y urbana recientemente decretadas, sancionadas y promilgadas en Colonbia. Se inspira nuestra propuesta en 1 as experiencias de Ralph Erstine, en el Eyber Wall de Newcastle, En $10 s$ proyectos Faitillas y Aguadillas de Jan Wampler, en Fuerto Fico, en el proyecto Santa Catalina de Victor Felli, en el Chaco, en el proyecto La Colmena de Julio Fovi, en Fanama, en las Unidades de Apartamentos flexibles en Upsala Suecia y en 1 a teorica pero no menos importante del grupo S.T.T.E, "Highrise of Homes".

Se ampara, esta propuesti, en la CONSTITUCION POLITICA DE COLOMEIA. Articulo 51, que dice: "Todos 105 colombianos tienen derecho a vivienda digna. El Estado fijara 1 as rondiciones necesarias para hacer efectivo este derecho y promover planes de $\checkmark j$ vienda de interes social, sistemas adecuados de financiacion a 1 argo plazo y formas asociativas de ejecución de estos programas de vivienda."

Contextualizaremos 1 as ideas de HAEFAFEN a nuestra realidad soriomultural, con nuestras tecnologías constructivas y posibilitando soluciones acordes a las tipologias de vivienda regi on 1 es.

La vivienda aqui planteada se compone de dos partes el SOFOFTE y I AS FAFTES SEFAFAELES, entendidas asia por Soporte, la parte de vivienda que no puede ser modificada por los lusuarios" estructura portante, entrepisos, techos, escaleras comunes, instalaciones Eletricas, sanitarias e hidraulicas comunes, muros divisorios de porciones de soporte (colindantes), etc..

For partes separables entendemos 1 os componentes de obra que 105 lusur i os pueden 1 ocalizar, cambiar de lugar, agregar, Etc. Es, entonces, en la configuracion de 1 a ressa dentro del soporte, su diseñ, construccion y decoracion en 1 a que los usuarios tienen 1. a oportunidad de participar activamente para que se materialice la libertad de expresion individual y familiar requerida para "häbitir" sul vivienda.

\section{1 ITINERARIO DE UNA FROPUESTA:}

2.1 .1 Los municipios, por intermedio de sus CONCEJOS iArticulo

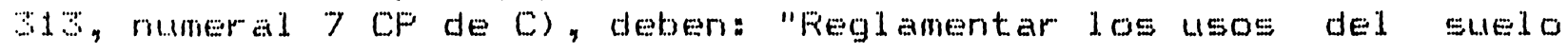


$y$, dentro de los limites que fije la ley, vigilar y controlar las actividades relacionadas con la construcción $y$ enajenación de inmuebles destinados a la vivienda". Y el Flan de Desarrollo a que estan obligados por la Feforma Urbana (Ley 09 de 1989) 105 municipios con poblacion superior a los cien mil habitantes, cuyo Articulo 2, numeral 4, les obliga incluir: "La reserva de tierras urbanizables necesarias para atender oportuna y adecuadamente 1 a demanda de vivienda de interess social y para reubicar aquellos asentamientos que presentan graves riesgos para la salud e integridad permonal de sus habitantes".

2.1 .2 Las arreas definidas, congeladas y adquiridas por los municipios se incluiran en sus "Baricos de tierra" (Articulo 70, Ley 09 de 1989), que entre otros fines está destinado por el Art. 10, Ley 09 de 1989 , según los 1 iterales b) "Ejecución de planes de vivienda de interes social"y m)"Reubicacion de asentamientos humanom ubicados en mectores de alto riesgo y rehabilitación de inquilinatos".

2.1 .3 La administración municipal dara prelación para 1 a construccion de las obras de infraestructura de servicios, como se 10 indica 1 a Constitucion Nacional (Articulos $366^{\prime \prime E l ~ b i e n e s t a r ~}$ general y 1 mejoramiento do 1 a calidad do vida mon finalidadem sociales del Estado....." 1 " 11 "Al municipio como entidad fundamental de la división politico-administrativa del Estado le corresponde prestar low servicios publicos...". Y el Articulo 47 de la ley 09 de $1989^{\prime \prime T o d a ~ p e r s o n a ~ o ~ g r u p o ~ d e ~ p e r s o n a s ~ t i e n e ~}$ derecho a solicitar los servicios públicos de acueducto, alcantarillado, energia electrica, gas, recolección de basuras $y$ telefono para $\$ u$ vivienda (...). En todo caso, las autoridades que suministren los servicios publicos definidos en el primer incimo preferiran las solicitudes de los ocupantes de viviendas de interms social".

2.1.4 como parte de 1 a infraestructura de servicios de la ciudad, 105 municipios, directamente, por intermedio de la Financiera de Desarrollo Territorial, o por intermedio del Fondo Municipal de Vivienda de Interess Social y Reforma Urbana (Ley os de 1991 , Capitulo V, Articulo 17) construyen "ESTRUCTUFAS DE SOFORTE" quE permitan la construccion de diferentes tipos de viviendas en eldas. Las estructuras de soporte por sus caracteristicas mas relievantes: multipisos, infraestructura de servicios contenida y flexibilidad, podrian entenderse como "lotes multifamiliares con servicios", donde el termeno se usa verticalmente varias veces (3?) para aumentar 1 a densidad $y$ acortar 1 as longitudes de redes de servicios, vias y transportes. Los costos de la estructura de soporte (1ote atereo) deben ser equivalentes al menor costo por terrenos a utilizar y a sus respectivos gastos de urbanización.

Las estructuras de soporte deben asegurar:

- Fuena localización con relacion a los equipamientos colectivos y 1. as fuentes de trabajo.

- Ordenimi ento urbano

- Densificacion de 1 a planta fisica de la ciudad y por tanto mayor economia en redes de servicios y transportes

- Infraestructura de servicios (sanidad ambiental en general)

-Estabilidad. 
La porción de terreno y/o soporte que utilice el desarrolio progresivo de cada vivienda puede ser cedido fparcial o totalmente) por el Estado romo subsidio familiar de vivienda en especie (Ley os de 1991) o arrendado a largo plazo con una tasa de arriendo de soporte: 1 a recuperación en este caso estaria a cargo de 1 as Empresas Fúblicas Municipales como cualquier otro servicio público. En este caso el subsidio familiar de vivienda se trasladaria a los materiales necesarios para la iniciación de Ia vivienda o simplemente vendido y financiado con credito blando En programas de infraestructura de servicios.

2.1 .5 Fara optar por la consecución del Subsidio Familiar de Vivienda (Nueva Folitica de Vivienda de Interes Social Ley o3 de 1.991) y de una Porción de soporte ante el municipio se conformaran Organizaciones Fopulares de Vivienda uley o9 de 1989, frt. 62) que asesoradas por el TNUFEE y el municipio conformaran grupos de trabajo social y tecnico para el desarrollo dE IOS TALLEFES DE DISERO FAFTICIFATIVO donde se tomaran 1 as decisones iniciales de planificación, programacion, diseño y monitoreo del plan de vivienda. Los acherdos iniciales generales se tomaran en forma democratica, segun reglamento interno de 1 a organizacion popular de vivienda, y se daré "liberted" asesor ada a 105 usuarios para aquel as decisiones de caracter individual.

2.1.6 En cada zona o sector de vivienda de interes social se Ueben crear CENTFIOS DE ACOFIO y venta de materiales, pues 1 a construccion progresiva de casas se encarece por 1 a consecucion "al meriudeo" de 105 materiales $y$ su transporte unitario y repetitivo. En Cali, por ejemplo, la Fundacion Carvajal tiene tres magnificas experiencias en $10 s$ barrios pobres del Distrito de Aguablanca, ha establecido Earicos de Materiales de Comstruceion que operan como concesiones utilizando locales de 1 a Fundacion para vender sus productos al consumidor final, 1 ibres Ue intermediarios y a los mejores presios posibles, con la ventaja adicional de ahorrarse el traneporte que se podra hacer er forma ecomomica al estar el banco de materiales cerca del sitio de la bora. La segunda experiencia se refiere a la creación de las plantes de insumos, donde las organizaciones populares de vivienda y mi corompresarios de 1 ä misma comuni lad fabrican $y$ venden insumos para 1 a construceion $y$, por último, 10 Talleres de Asistencia Fermanente en Construcion: ingenieros, arquitectos $y$ estudiantes de arqujtectura e ingenieria asesoran gratuitamente a 1 as commidades en 1 a construceion de sus viviendas.

Fockr ia pensarse que 10 municipios redujeran los implestos (IVA) a los wentros de acopio o bancos de materiales con destinacion exclusiva a 1 as organizaciones populares de vivienda.

2.1.7 Las entidades de credito iritegrantes del sietema Nacional de Vivienda de interes social firinciar án $10 s$ creditos para pagar Ia porcion de soporte y/o materiales de 1 as partes separables en la construción inicial de la casa que excedan en el costo al valor del Subsidio de Vivienda.

2.1.9 Los usuarios se trasladan a sus nuevas casas y continuan su desermollo dentro de 1 a estructura de eoporte. Como adguirir una cas suficientemente grande desde el primcipio es casi imposible, este sietema posibilita la adquisicion paulatina de los 
componentes y usarlos sobre una estructura estable. EE factible utilizar uria mayor area inicial de vivienda, cerrando el contorno de la porcion de soporte sin divisiones interiores. (ver dibujo anexo)

\section{SISTEMA CONSTRUCTIVO}

E1 sistema constructivo de 1 as ESTFUCTURAS DE SOPORTE puede variar de una region a otra, pero debe cumplir con 1 as siguientes determinantes:

Gue sea totalmente portante $y$ estructuralmente autónomo, sin dependencia de las unidades de cierre de las viviendas que se instalen posteriormenete.

Wue permita flexibilidad en los espacios para vivienda.

Que sea apto para 1 a coordinación dimensional y modular.

Dete permitir en ella, ademas de vivienda otros espacios complementarios como tiendas, talleres, guarderias, etc...

Que posibilite el uso de diferentes materiales de muro, piso, cubierta, y acabados a 1 as futuras viviendas.

Que se adapte a diferentes topografias.

Due se consigan fácil mente los recursos materiales y humanos para la construcción en el sitio de las obras.

Que sea económico.

LaE UNIDADES SEFARAELES tambien deben cumplir algunos requisitos: Eajo costo de energía para su producción y montaje.

Fecurso natural renovable.

Feutilizacion $y$ biodegradabilidad.

Ecomomia de coeto.

Adaptabilidad tecnol ogica al usuario.

"...posiblemente el rasgo más definitorio de 1 a existencia de una arquitectura regional o nacional conmimta en el demarrollo de una arquitectur que entronca con una tradición concreta. $Y$ que, con actitud critica, se renueva y moderniza continuamente con el paso del tiempo y la evolucion general"

Josep Maria Montaner

En nuestra region existe una gran tradición constructiva del bahareque (muros de entramado organico y un recubrimiento). Los pobladores indigenas construian empalizadas cubiertas de paja, en 1 a epoca colonial se conoció la construcción de muros de tapia pisada (tierra sin coser), mas adelante, y por tratarse de una zona susceptitle a los sismos, se cambió esa tradición por una mixta de piso bajo en tapial y piso alto en bahareque que se conocio como estilo "temtiorero" por su buen comportamiento en 1 os temblores de tierra, luego se pass a la construcción total en bahareque con 1 a que se construyeron ciudades enteras y edificios hasta de seis pisos. Este bahareque cuya estructura se hace de guadua y madera aserrada recubierta con barro, tablas, lámina metalica o morteros, ha trabajado muy bien en los eismos por tratarse de estructuras livianas y algo flexibles, sinembargo las estructuras de bahareque en edificios de varios pisos lmás de dos) con el tiempo se han deteriorado por la acción del agua, el sol y sobretodo, por la dificil unión entre los diferentes pisos de la estructura. 
Informes de la Construcción, Vol. 44 n. 424, marzo/abril, 1993

El deterioro de estas estructuras ha 11 evado a $10 s$ propietarios a intervenciones de consolidacion recientes donde mezcian dos tecnologias constructivas comunes en la region, el bahareque de guadua y madera $y$ el concreto reforzado. Aparece entonces la rueva tradición constructiva donde los porticos de concreto hacen la parte rigida y estatile y el bahareque de los muros liberado de su función estructural toman la parte "flexible".

lnepirados en esta nueva tradición constructiva regional planteamos nuestra propuesta para la construccion de 1 a vivienda de interes social. Estructura de soporte en porticos tridimensionales de concreto reforzado y muros en paneles prefabricados de guadua y madera, tecnologia constructiva que cumple fielmente las determinantes que exigiamos para los soportes y las unidades separaties.

\subsection{LA ESTRUCTURA DE SOPQRTE}

Estará compuesta por porticos multiples de concreto reforzado sobre zapatas del mismo material ligadas por vigas de rigidez. Situada en una malla de $30 \times$ $x 0$ cms. 1 as columnas formaran espacios de $3.60 \times 3.60$ mts. y voladizos de 1.20 mts. Entre las columnas se colocaran las vigas de carga con "aletas" o "pestañas" que soportaran los entrepisos que estaran estructurados con guaduas dobles (una sobre ot.ra) cada 30 cms., sobre las guaduas se colocardesterilia foudua abierta en forma laminar) sobre la esterilla una parrilla de alambron (30 $x 30$ ciss.) y sobre esta una capa de $3.5 \mathrm{cms}$. de mortero de cemento. Los tecnicos deben tener en cuenta al gunos requisitos minimos al diseñar estructuras de soporte como 1 as propuestas: Forma simetrica en lo posible, muros rigidos o columas especiales en las esquinas, localizar siempre miembros estructurales en el perimetro, $y \mathrm{~s}$ se diseñan estructuras escalonadas tener en cuenta contimuidad en 1 as columnas $y$ que el escalonamiento coincida con 1 a modulacion de 1 as crujias.

Hay dos motivos fundamentales por los cuales se plantea ura solucion mixta (aparte de la cultural), la primera se refiere a que las estructuras de soporte deben quedar algún tiempo a la intemperie $y$ egegurdo por que 1 as estructuras de soporte deben brindar una gran flexibilidad espacial que solo se consigue quitando 1 a condición estructural a $10 \mathrm{~s}$ muros.

\subsection{LAS UNIDADES SEPARAELES}

Los muros, preponderarites en 1 as unidades separables, se proponen en forma de paneles modulares de guadua y madera, similares a $10 s$ que hemos experimentado en vivienda unifamiliar de baja altura, que se construyen asi: definidas las medidas en la malla de situacion ( $30 \times 30$ cons.) se inicia en la planta de produccion o a pie de obra con la construcción de un marco en madera aserrada (de seccion rectangular que permite mejor alineacion y nivelacion en obra) este marco se completa con pies derechos de guadua sobrebasa (diametro aprox. $8 \mathrm{cms}$. ) cada $30 \mathrm{cms}$. La estructura se forra con esterilla de guadua y malla de gallinero o malla de revoque si es que los päreles se revoraran posteriormente en 1 a obra, o se recubre con carton madefles o laminas de fibrocemento para muros interiores sin revoque. El revoque, acabado final con 
mortero de cemento se hace en dos tiempos para mayor adherencia. Los paneles tienen una altura de 2.40 ints. y segun 1 as necesidades de la obra se usan anctios de 60, 90, 120, 150, 180 y 210 cms. considerando que son má económicos 10 de mayor anctio por ser la guadua mas barata que la madera aserrada.

Los varios pära puertas y ventanas por quedar rodeados de madera aserrada permiten 1 a colocación de diversos materiales de corramiento al gusto del usuario. El revoque de mortero de cemento permite ser piriado o usar otros tipos de acabados.

Los paneles (parte de muro) se unen entre $5 i$ con clavos y tornillos con tuerca y a las columnas y vigas de carga por medio de chazos que se han dejado previamente en la estructura de soporte.

No debemos olvidar que el fxito de la construceion con madera y guadua esta 1 igado a 1 a forma como procesamos estos materiales

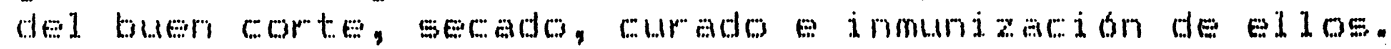

La cubierta se recomienda con estructura de guadua o madera y tejas de fibrocemento, es un techo liviano, economico y de gran aceptarion 1 ocil.

For tratarse de una region de alto riesgo sismico esta tecnologia constructiva es apropiada porque la estructura tipo "jaula" actua bien contra cargas horizontales en cual quier dirección. Los muros de guadua y madera son muy livianos y adecuadamente flexibles. Los porticos mltiples aprovectian 1 as ventajas de 1 a continuidad, tres o mas columnas soportan las vigas y bstas se $1 \dot{i g a n}$ rigidamente a 1 as columnas. Los póticos múltiples absorben cargas laterales con suma eficiencia.

Con relacion a 1 a topografia de ladera, 10 a porticos t.widimensionales, se prestan para soluciones escalonadas.

\subsection{EL DISENO ARQUITECTONICO:}

Gasados en 1 a malla de situacion y en la modulacion estructural propuesta de $3.60 \times 3.60$ mts. para 1 . 35 . para 1 os margenes y definidas las poreicones de soporte para cala ura de 1 as familias del grupo de trabajo, 1 os tecnicos pueden archivar en el ordenador diversas posibilidades de modulos espaciase que podrian usarse en los talleres de diseño warticipativo localizando los diferentes espacios de 1 a casa en la porcion de soporte. Un diseño alternativo seria: decidir el espacio inicial de la case ("embrion") entre los tecnicos y 105 lusurios luego definir el corramiento contorno de 1 a porcion de soporte y por ultimo dejar total libertad a 10 s usuarios en 1 a compartimentacion futura del espacio, para esta ultima etapa se

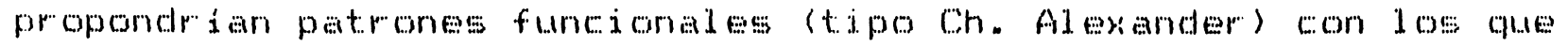
10 usuarios puedari definir los espacios de su casa en un proceso I Ent: y seguro.

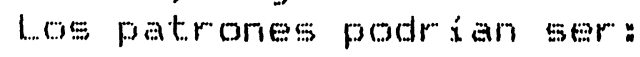

-.. Todoe 105 espar...ios deben guedar con iluminacion y ventilacion

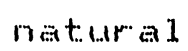

.... El comedor debe estar dentro o adyacente a la cocina

-. La roperia no debe dar a 1 a calle

.. Resulta practico reunjer las zonas húmedas

.... Cadia alcoba debe tener entrada independiente, etc. 
Los técnicos continuan la asesoria y monitoreo del programa y de esta manera, "Los arquitectos más que definidores, nos convertiremos en diseñadores de posibilidades, dentro de las cuales 1 a gente encontrara sus propias definiciones" Sean Wellesley-Miller.

\section{VENTAJAS DE LA SQLUCION FROPUESTA. RESUMEN:}

- Las ciludades pueden controlar su crecimiento, densificando. - Las ciudades utilizan mejor sus servicios públicos.

Se desilinda, en parte, el diseño urbano y el arquitectónico, mejorando Ia espacialidad urbana. Se logra unidad con los soportes operando como pautas y la variedad de materiales, texturas y colores enriqueceran la vivienda.

-. Se distribuyen mejor los equipamientos colectivos de la ciudad. -La vivienda es economica porque permite ser subsidiada.

- La vivienda es económica porque los materiales se usan racionalmente, los propietarios no necesitan demoler partes de la otra para hacer modificariones iniciales como sucede en la vivienda seriada y uniforme.

-..Fosibilite la utilización de una mayor area de vivienda, cerrando el contorno de la porción de soporte sin divisiones interiores en 1 a primera etapa.

-Hace posible la industrialización de componentes constructivos livianos y 1 a reducción de sus costos.

- Se hace factible el uso de un mayor numero de materiales y tecrnicas constructivas al interior de la estructura de soporte. - Aceleraria la industrialización de la construcción, por la recesesdad de producir componentes conetructivos compatibles en di mensión y sistema de ensamblaje.

- Fermite la participacion de los usuarios en la configuracion de sus casas a partir de la utilización de "módulos espaciales" r..ompatibles entre si y con la estructura de soporte. Se podran distribuir casas diferentes en porciones de soporte iquales.

- El desarrollo progresivo es parte de la logica del sistema como se dijo atrás, los usuarios no tienen capacidad inicialmente para adquirim las abreas que necestan, pero de este modo van creciendo y enriqueciendo su casa de acuerdo a sus posibilidaes y gustos.

Favorece la vida comunitaria, compartiendo servicios, amotlamientos, espacios de recreación, etc. sin detrimento de la independencia en cada vivienda. Seren $10 s$ tecricos los que deben atinar en la programación y diseño de los conjuntos y sus respectivas estructuras de soporte. La riqueza y variedad dentro del orden dado por las estructuras de soporte se deja a la imaginacion popular: 1 a combinación de codigos eruditos y vulgares asegura 1 a creación de un entorno humanizado.

La ciudades de soportes seran las ciudades del azar, el diseño, el tiempo y la memoria. 


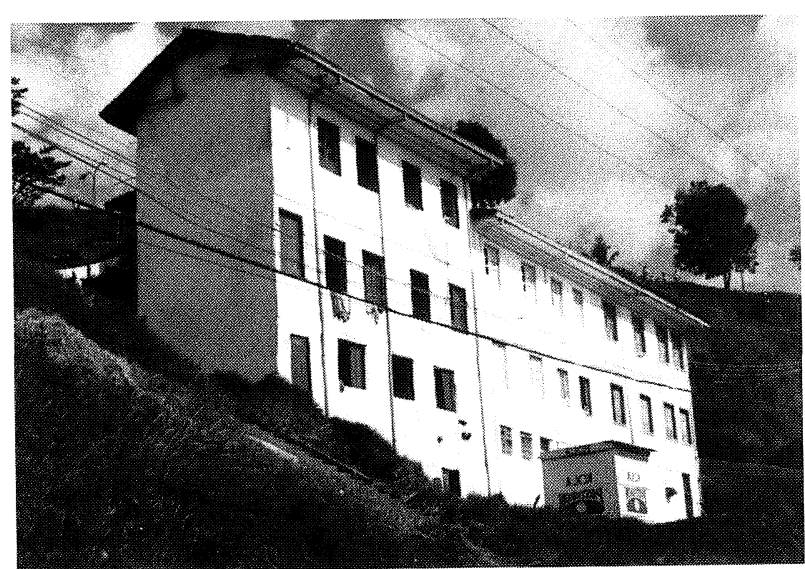

Edificios de bahareque.

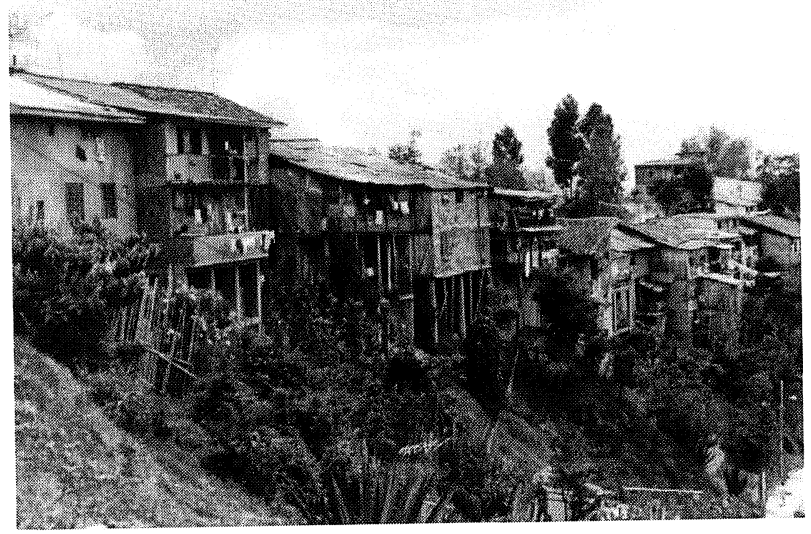

Estructuras de bahareque deterioradas y reforzadas.

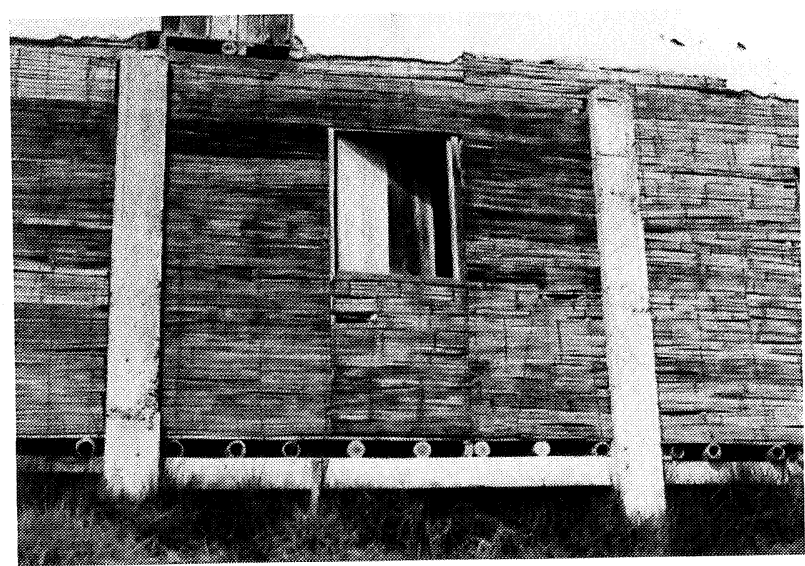

Detalle de refuerzo usando concreto armado.

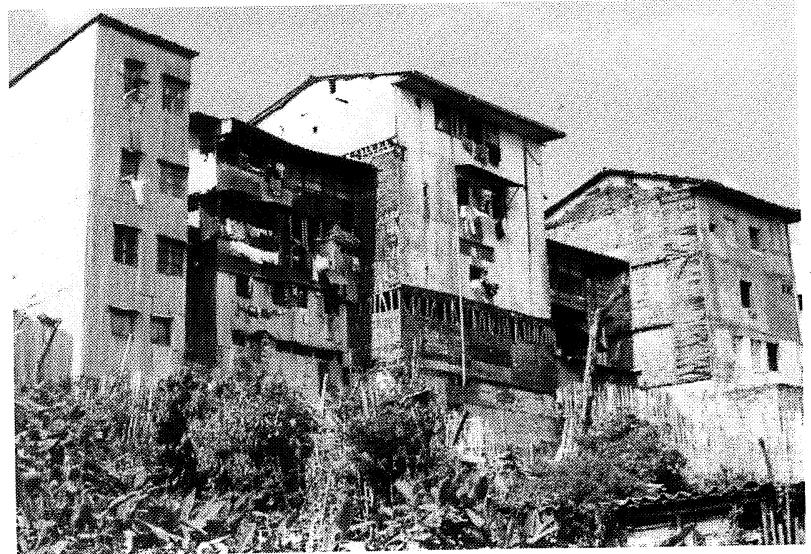

Estructuras de bahareque deterioradas.

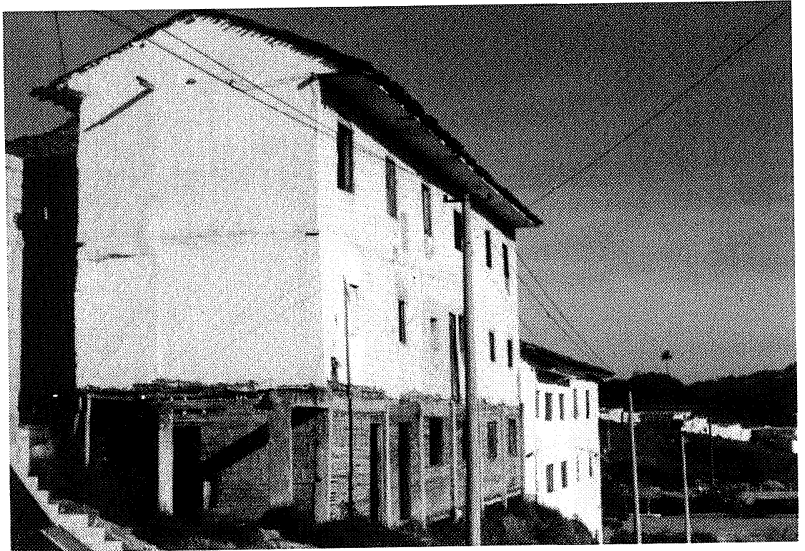

Bahareque consolidado.

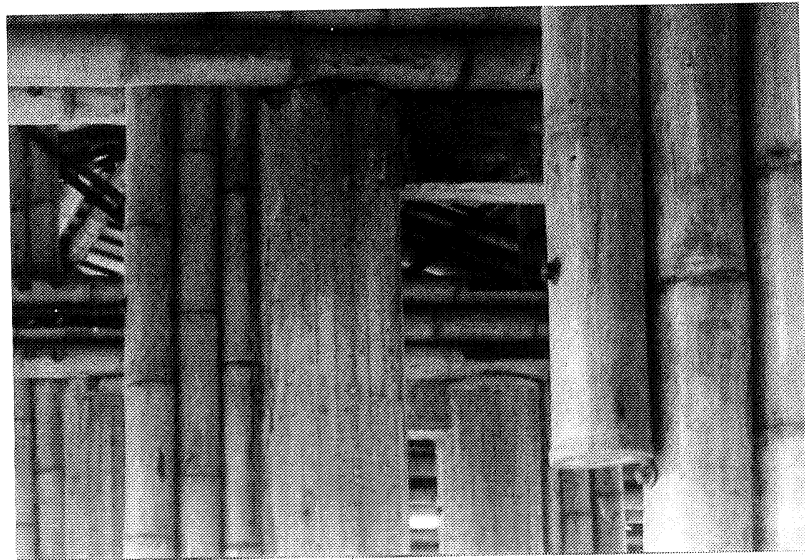

Estructuras de concreto y guadua, Arq. Simón Vélez Jaramillo. 


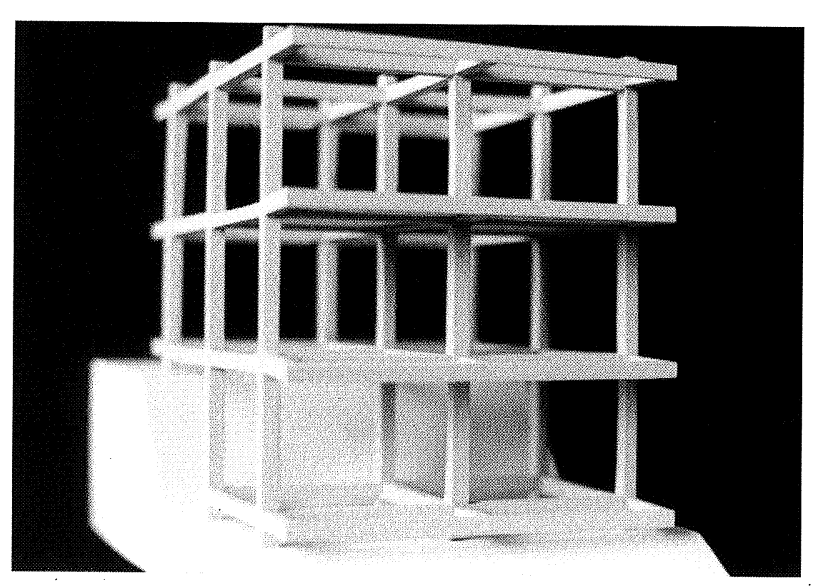

Maqueta estructuras de soporte.

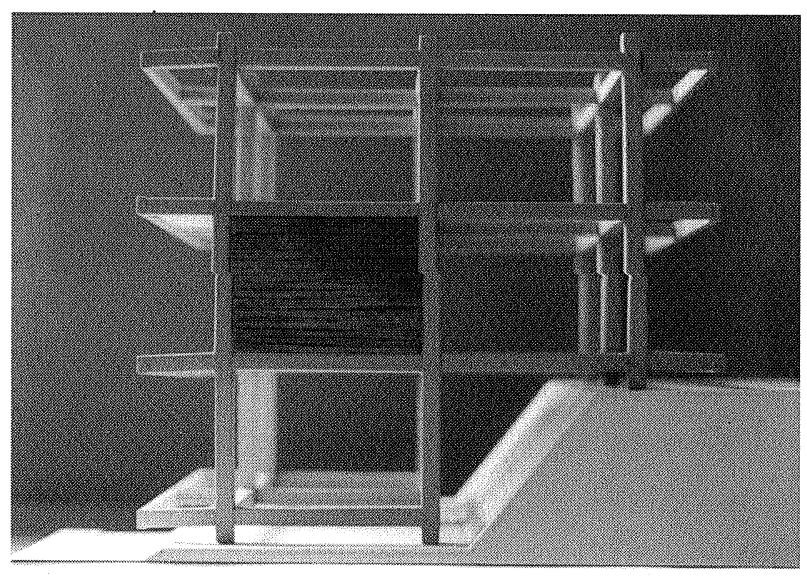

Maqueta estructura de soporte y unidades separables.

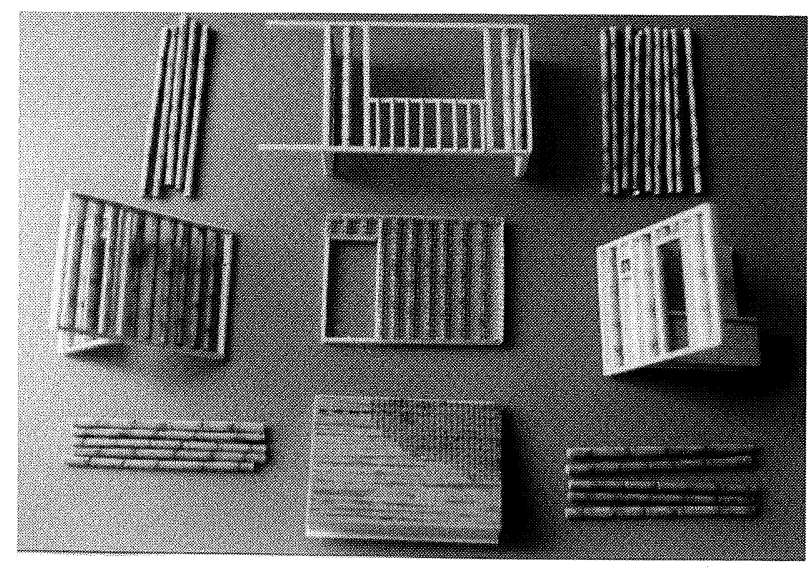

Maqueta unidades separables.

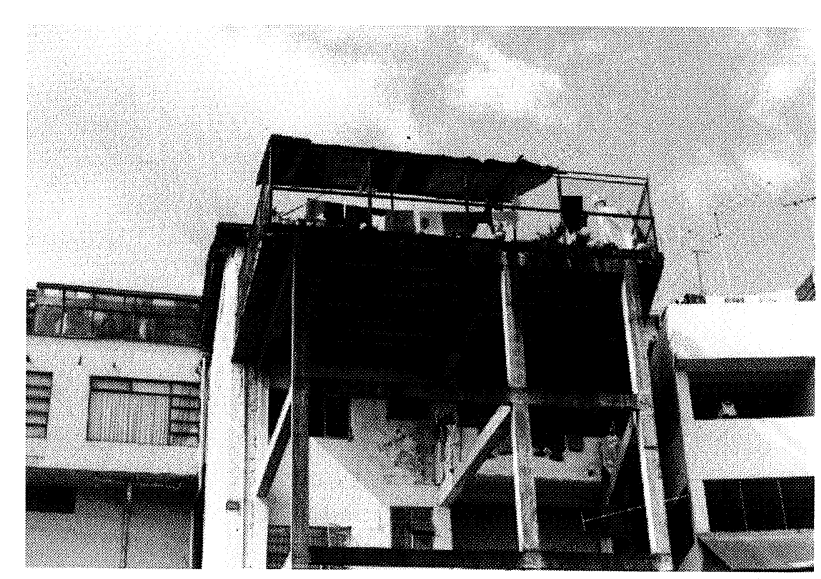

Estructura de pórticos múltiples en desarrollo. 

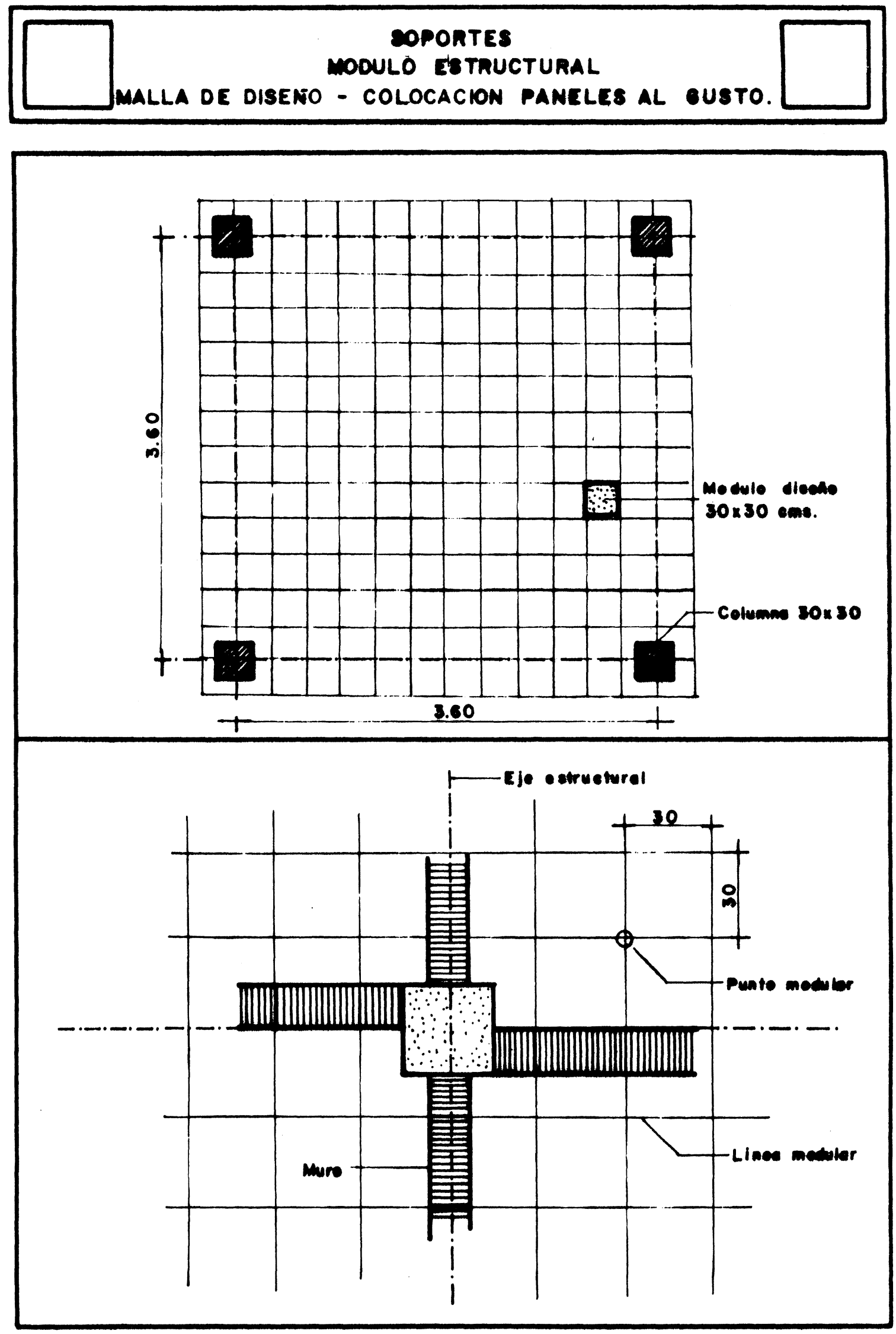

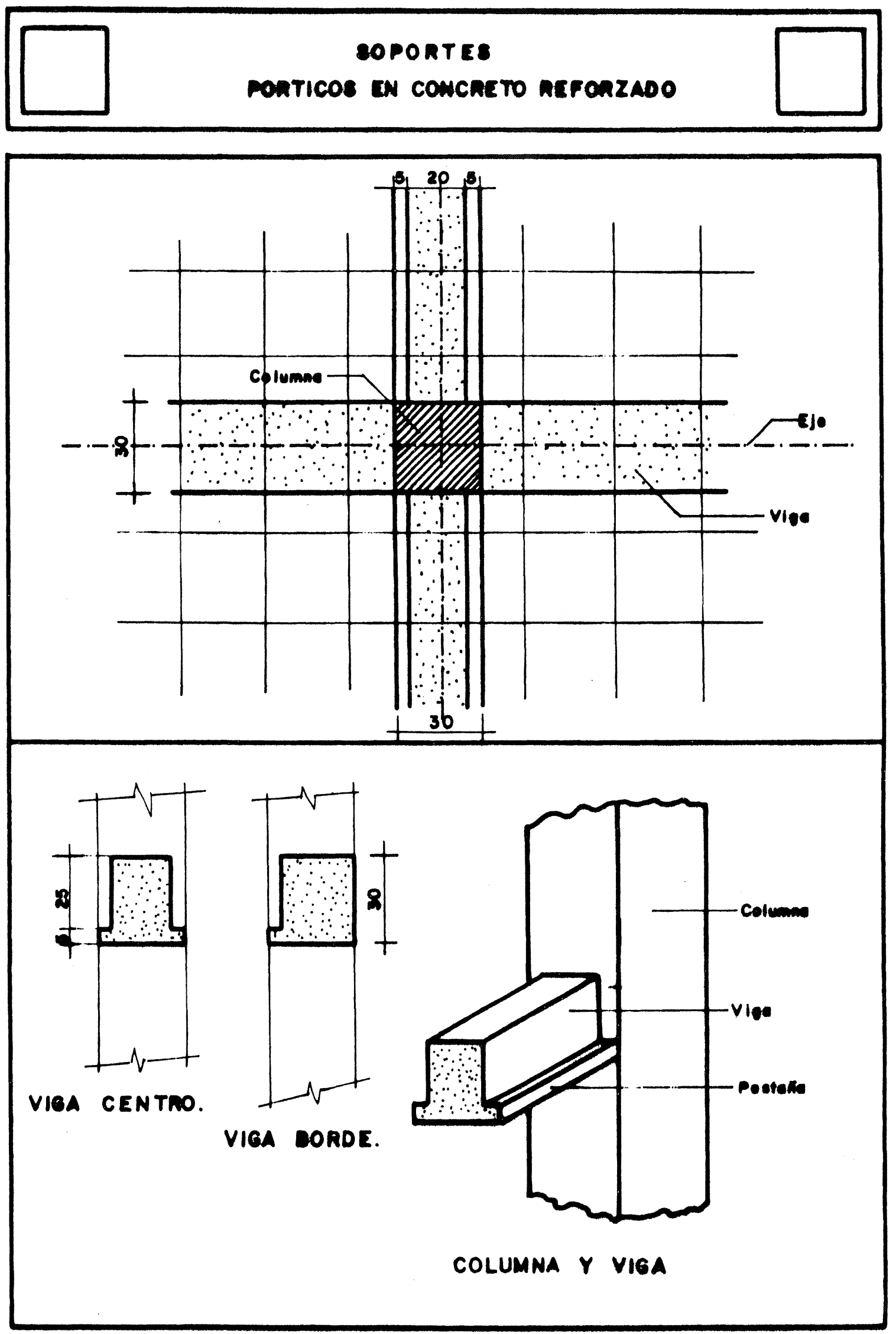


\section{SOPORTES}

COMPONENTES DE ENTREPISO-ZONA Y MARGEN-
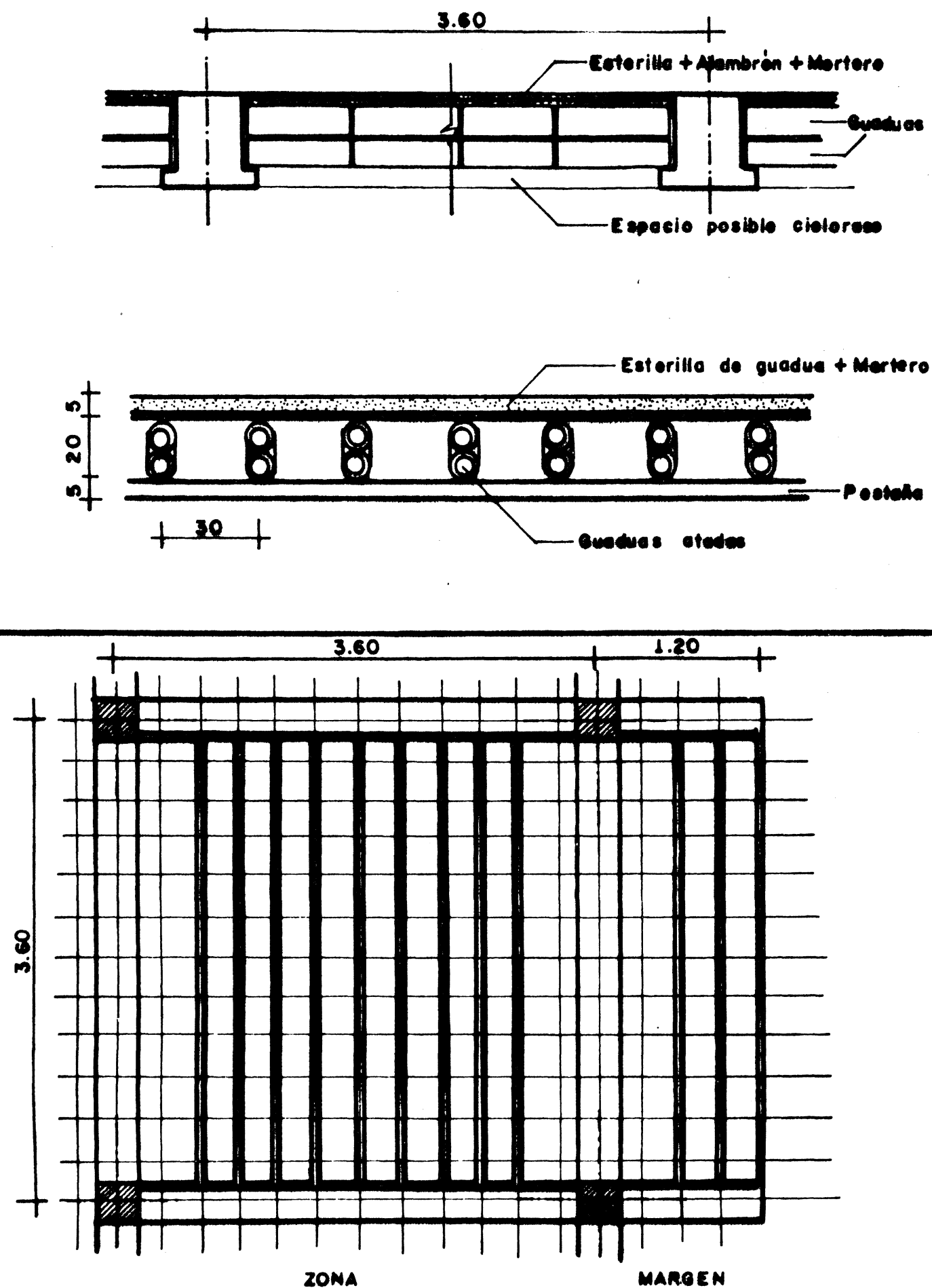

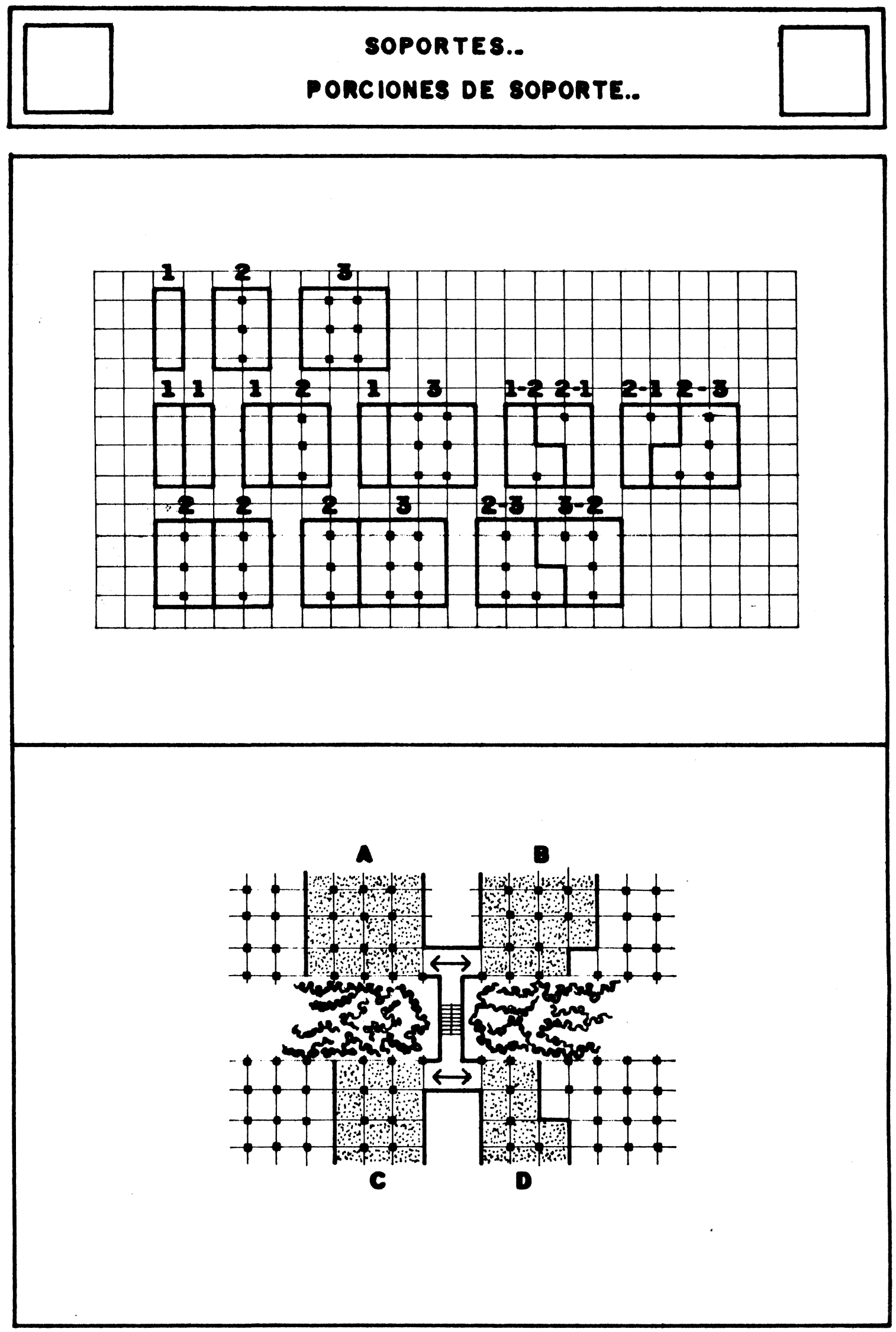

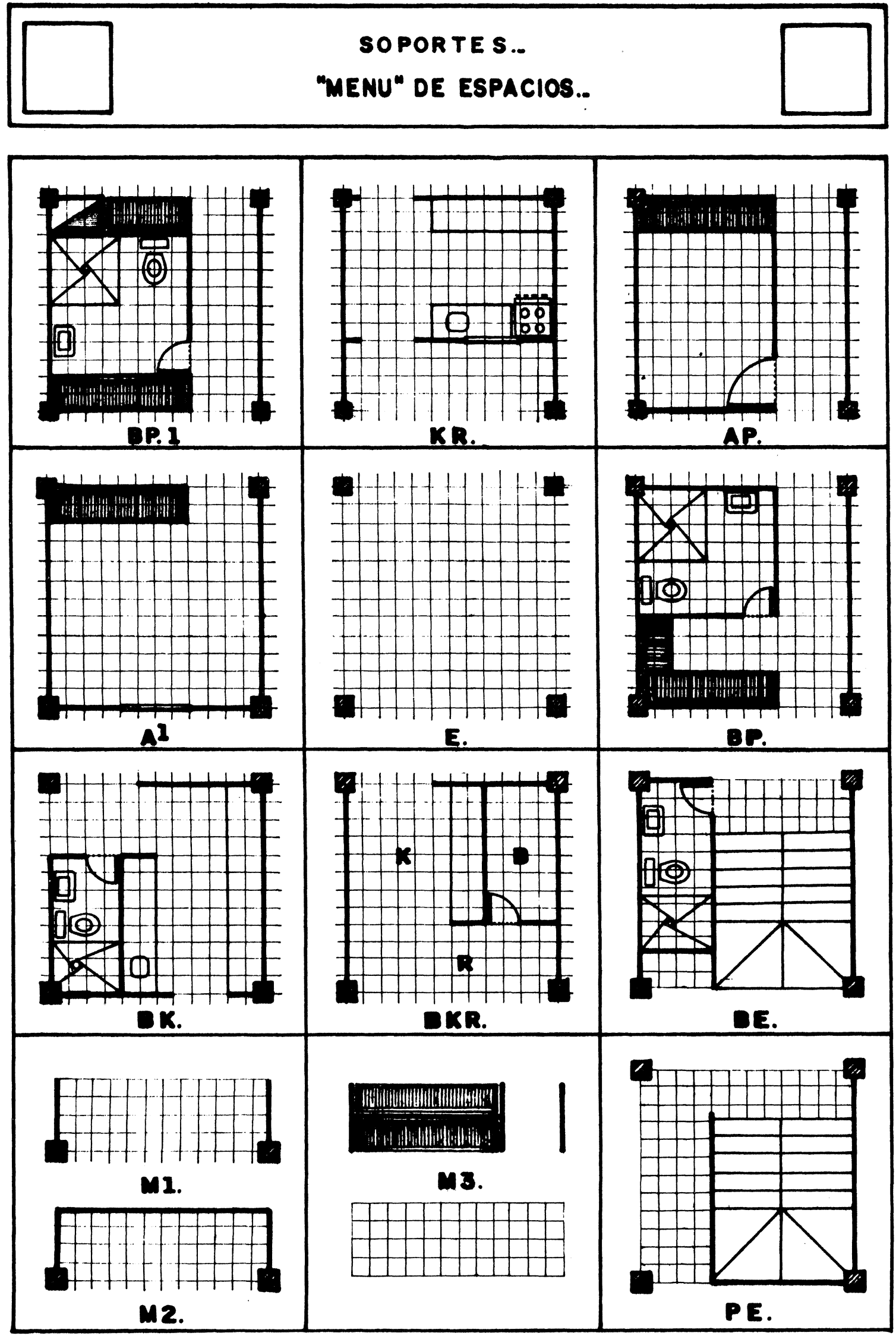

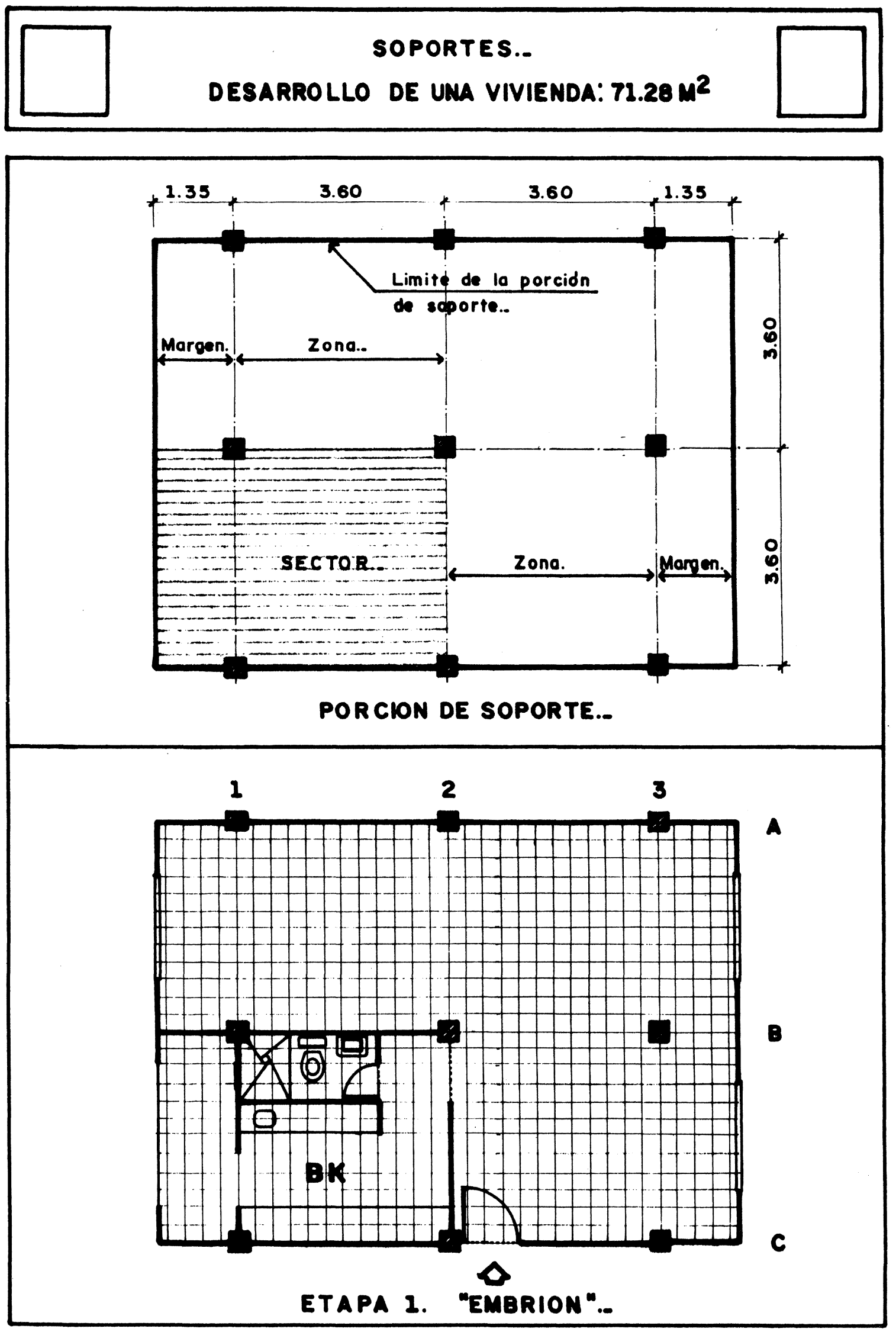

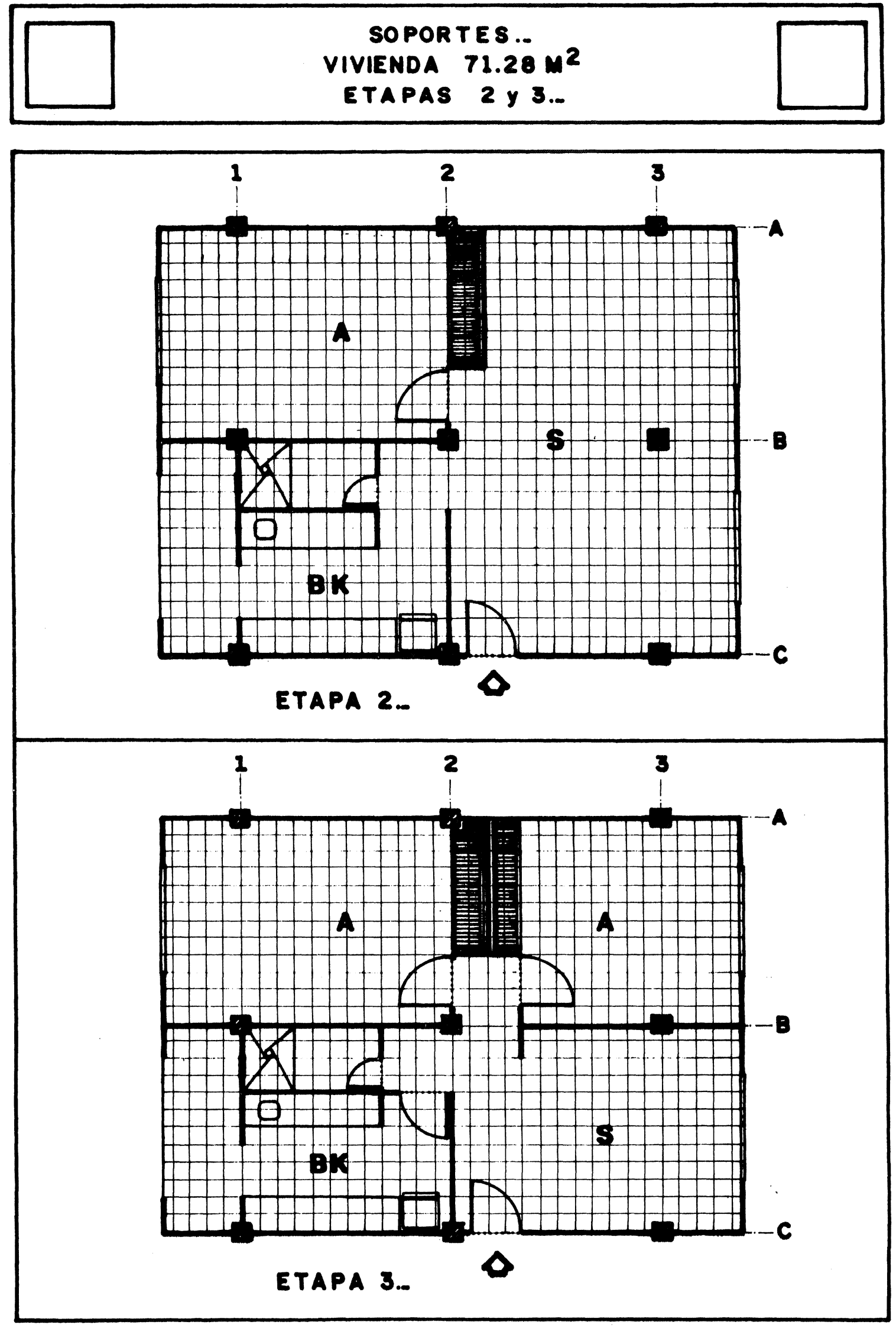

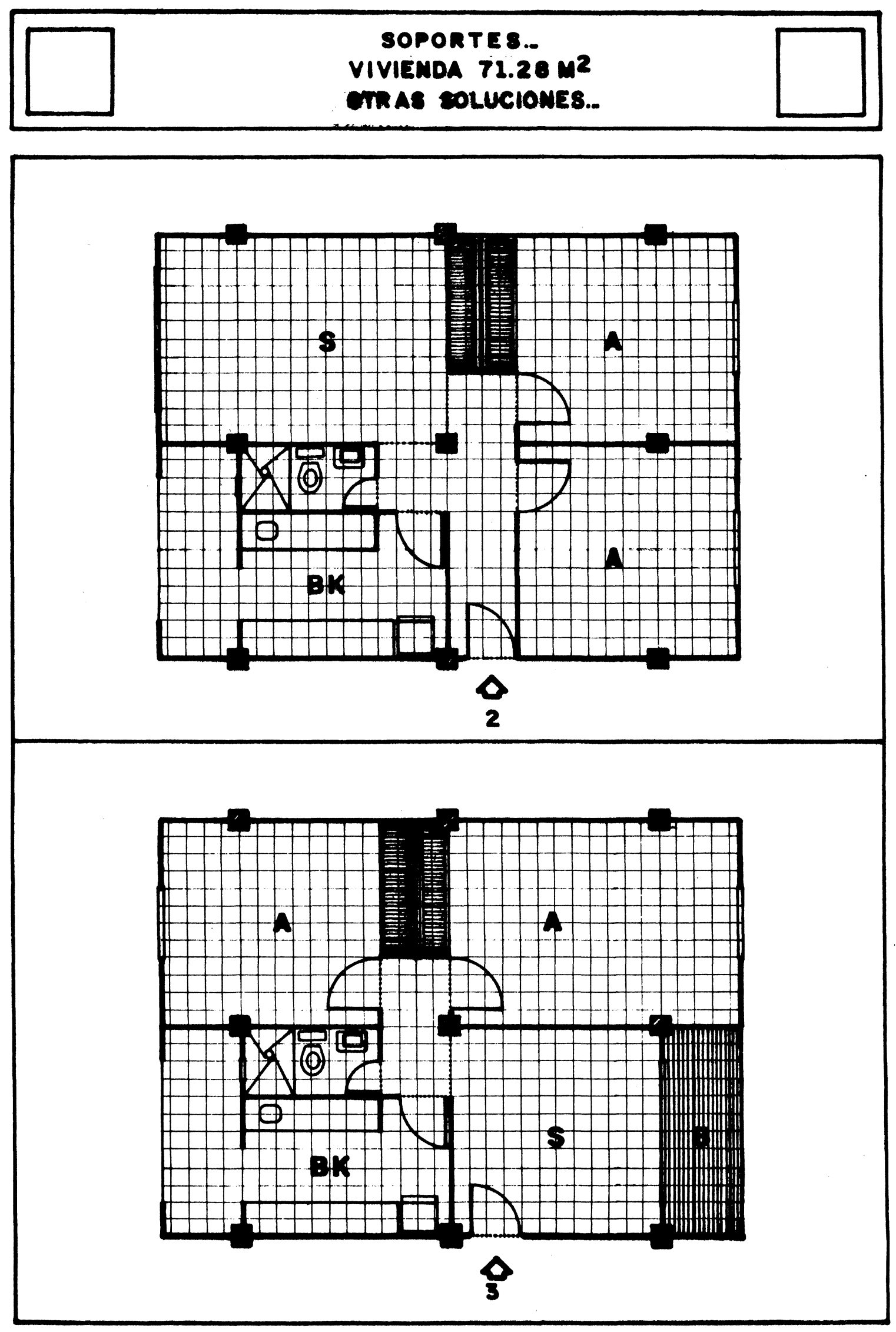

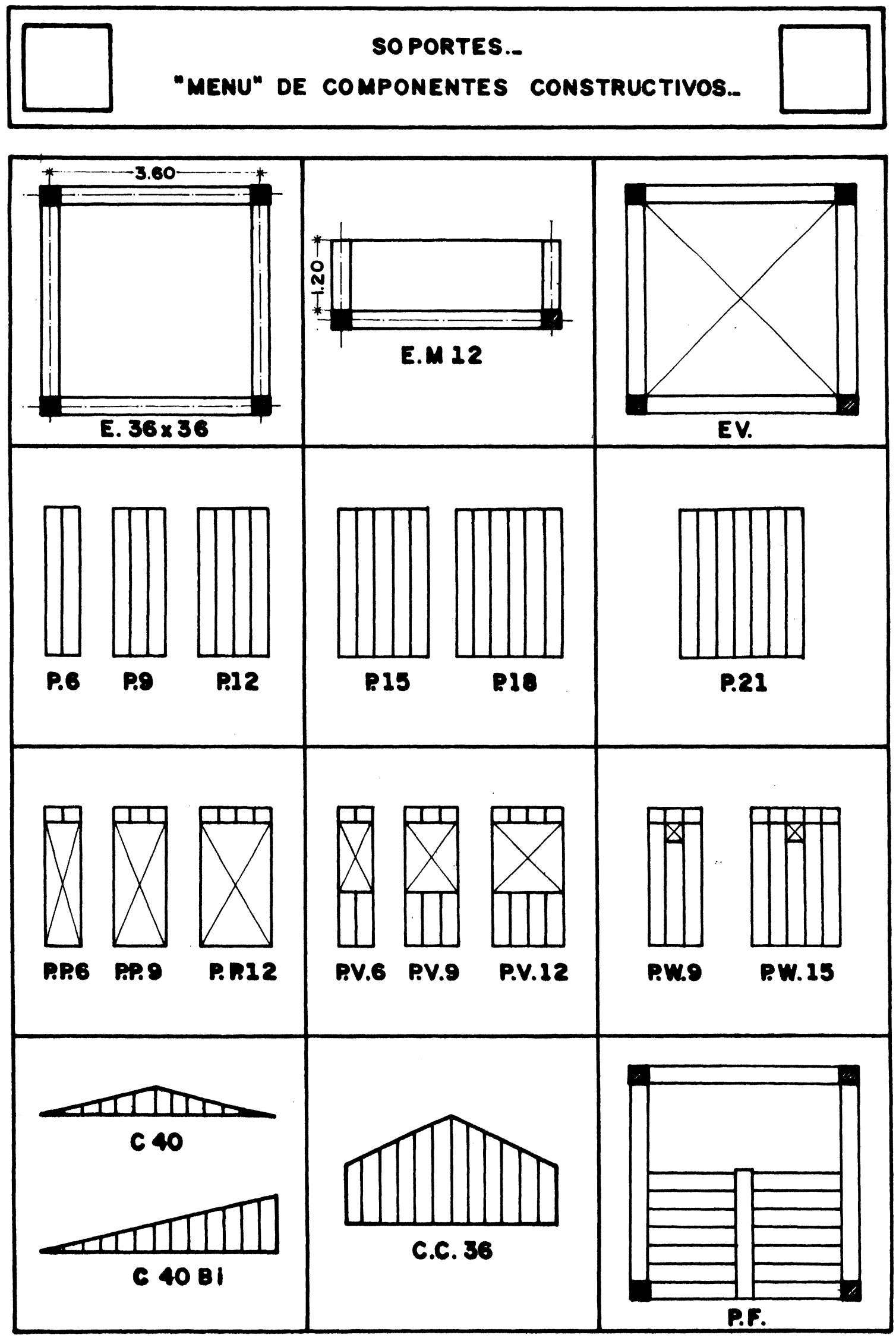

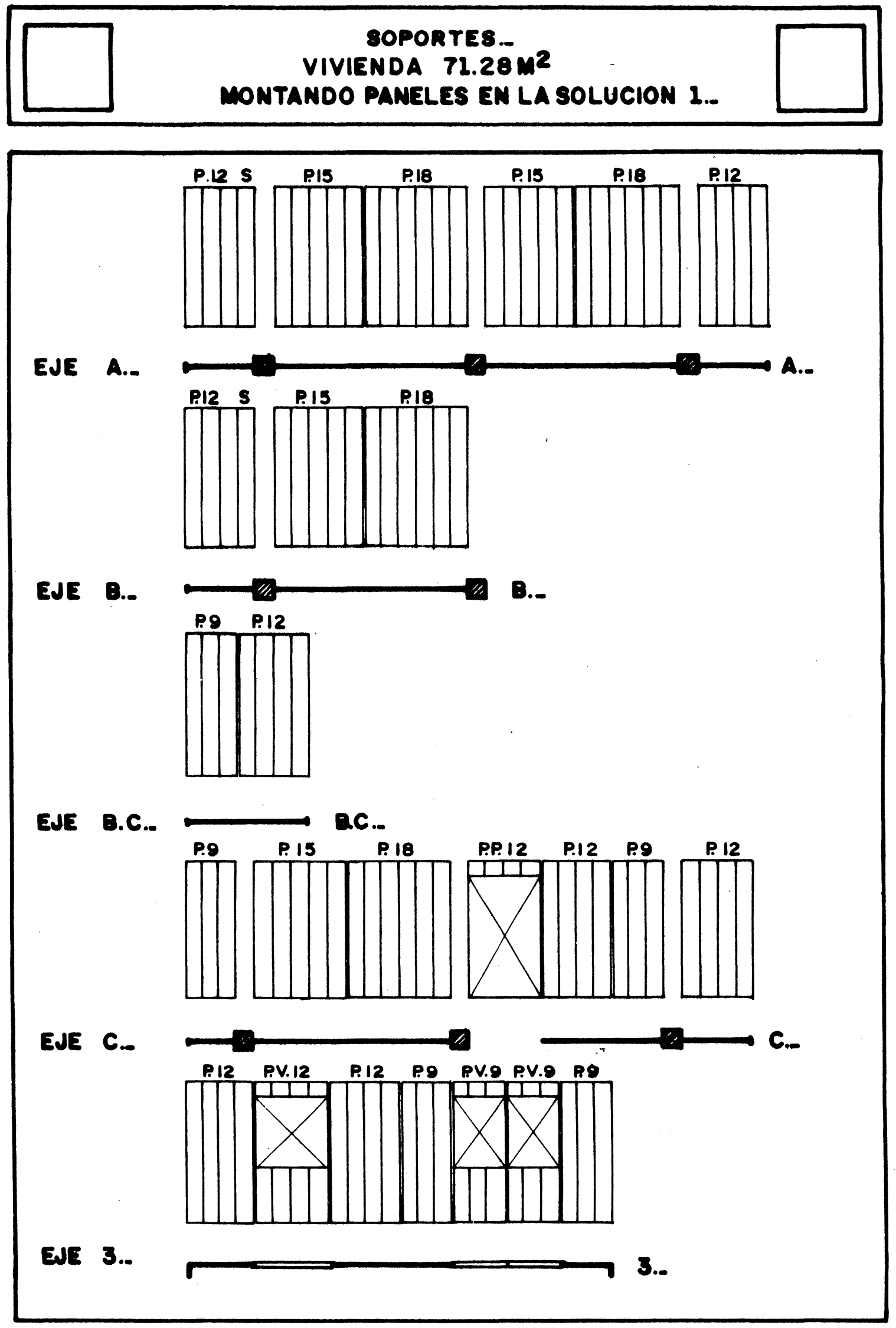


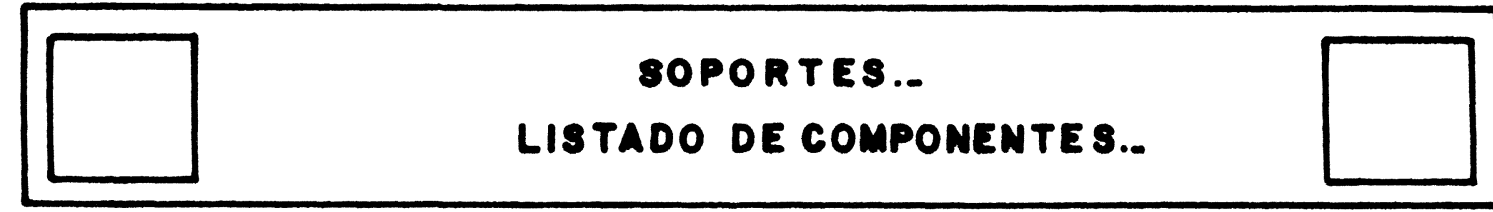

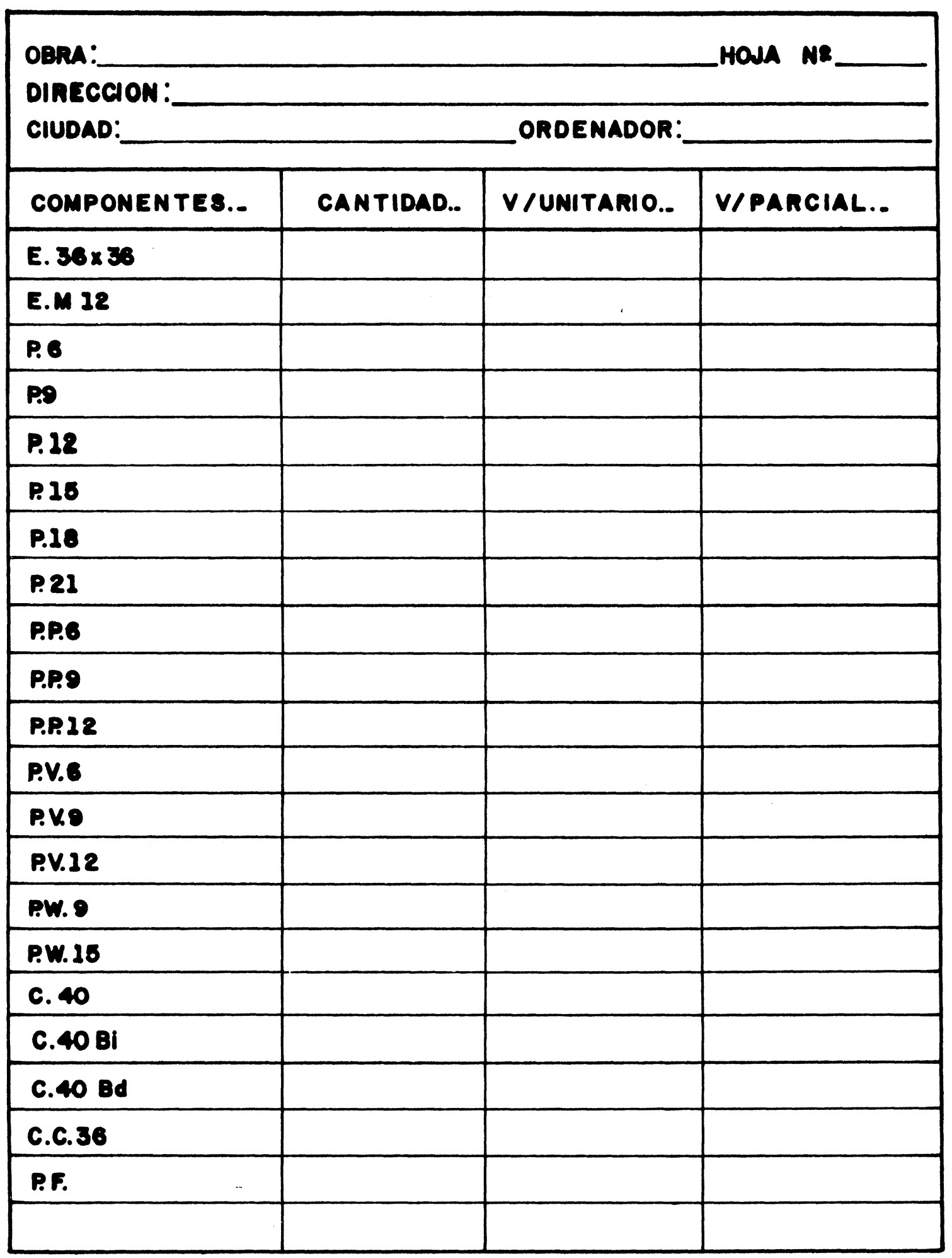




\section{BIBLIOGRAF IA DE CONSULTA}

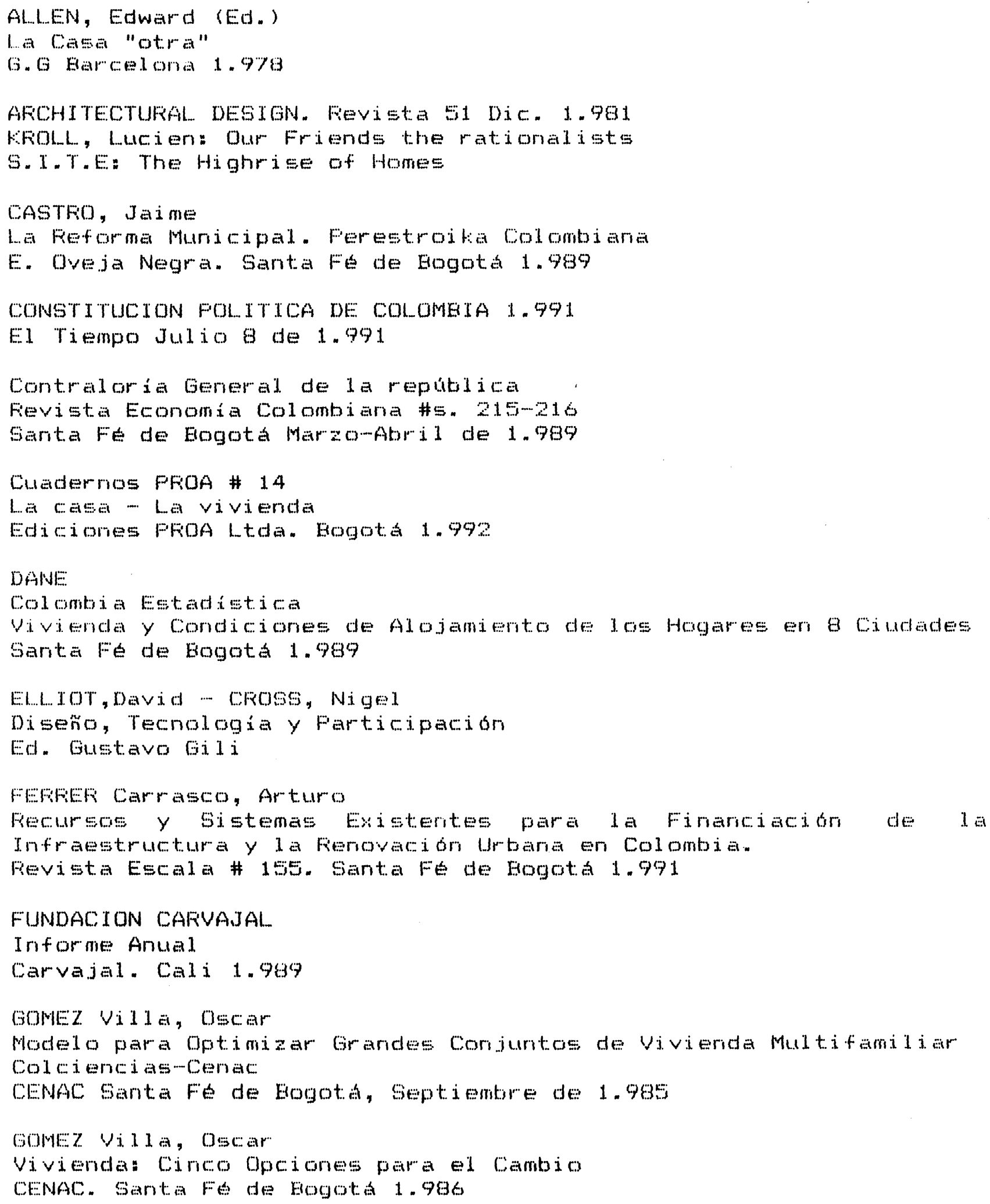




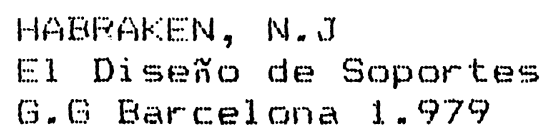

HAEFAAEN, N.J

Smportes una Alternativa al Alojamiento de Masas

Alberto Corazón, Editor. Madrid 1.975

HE TDEGGER, Martin

Construir Habitar Fensar.

Fievista Ingeni ar" \#6. Märizales 1.991

INUFEE:

Disposiciones LEgales sobre la Nueva Folitica de Vivienda

Ley or de 1.991

Ministerio de Desarrollo Económico

Santa Fe de Bogota 1.991

MENDEZ, Al Exis Y BOL TGAN, Mar i VEI

Automatizacion de Soluciones de Edificios de Vivienda: Une Herramienta para El Diseño.

Fevista Arquitectura y Urbanismo Vol. VTI \# 4. La Habana 1.986

MOGOLLON, Jaime - DIAZ, Gustavo

Sistema Normalizado en Guadua y Madera

Fevista FFOA \# 401

Ediciories PROA L.t.da. Bogota

MOOFE, Chardes, ALLEN, Gerard y LYNDON, Donlyn

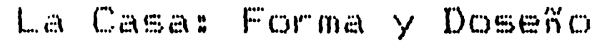

Ed. Gustavo Gili

NOFBEFG SCHULZ, Christian

Exi atencia, Espacio y Arquitectura

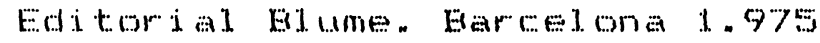

REFOFIMA UREANA

LEY OS de 1.989

Edicion "Fir ata"

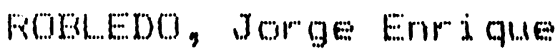

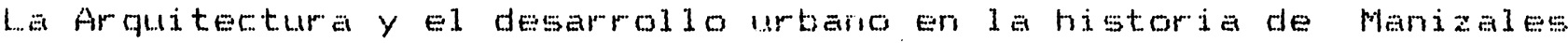
$1.946-1.930$

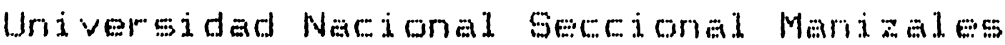

SOLo, Tova Mar ía

Vivienda Fopular en un Contexto Ar quitestomico

Cuadernos de Arquitectura \#s. 13 y 14

Fievista Escala. 